\title{
Evaluation of cell death mechanisms induced by the vascular disrupting agent OXi4503 during a phase I clinical trial
}

\author{
J Cummings",', M Zweifel ${ }^{2}$, N Smith', P Ross ${ }^{3}$, J Peters ${ }^{3}$, G Rustin², P Price ${ }^{4}$, MR Middleton ${ }^{5}$, T Ward' and C Dive' \\ 'Clinical and Experimental Pharmacology Group, Manchester Cancer Research Centre, Paterson Institute for Cancer Research, University of Manchester, \\ Manchester M20 4BX, UK; ${ }^{2}$ Department of Medical Oncology, Mount Vernon Cancer Centre, Middlesex, Northwood HA6 2RN, UK; ${ }^{3}$ Drug \\ Development Office, Cancer Research UK, $6 I$ Lincoln's Inn Fields, London WC2A 3PX, UK; ${ }^{4}$ Academic Department of Radiation Oncology, University of \\ Manchester, The Christie NHS Foundation Trust, Manchester M20 4BX, UK; ${ }^{5}$ Oxford Biomedical Research Centre Cancer Theme, University of Oxford \\ Department of Medical Oncology, Churchill Hospital, Oxford OX3 7LJ, UK
}

BACKGROUND: OXi4503 is a tubulin-binding vascular disrupting agent that has recently completed a Cancer Research UK-sponsored phase I trial. Preclinical studies demonstrated early drug-induced apoptosis in tumour endothelial cells at I-3 h and secondary tumour cell necrosis between 6 and $72 \mathrm{~h}$.

METHODS: To capture both possible outcomes of OXi4503 treatment on cell death, plasma samples for analysis by M30 and M65 ELISAs, which measure different circulating forms of cytokeratin 18 as biomarkers of apoptosis and necrosis, respectively, were collected from patients entered into the trial at early (4/6 h) and later time points (24h, day 8 and day I5).

RESULTS: OXi4503 induced a selective dose-dependent elevation in M30 antigen levels (apoptosis) at $4 / 6 \mathrm{~h}$ and a similar elevation in M65 antigen levels at $24 \mathrm{~h}$ (necrosis) consistent with its preclinical cell death profile. For the purposes of investigating potential biomarker relationships to patient characteristics, the trial population was divided into three groups based on radiological and clinical response: (a) early progression, (b) progressive disease and (c) stable disease (SD)/partial response. A significant increase in antigen concentrations was measured by $\mathrm{M} 65$ at $24 \mathrm{~h}$ in the SD group compared with the two other groups $(P=0.015$, mean increase 30.9\%).

CONCLUSION: These results provide pharmacodynamic evidence of drug mechanism of action in cancer patients and highlight the M65 ELISA as a potentially useful biomarker assay of response to OXi4503.

British Journal of Cancer (2012) I 06, 1766-177I. doi:I0.1038/bjc.2012.165 www.bjcancer.com

Published online 26 April 2012

(C) 2012 Cancer Research UK

Keywords: OXi4503; vascular disrupting agent; phase I trial; cell death mechanisms; M30 ELISA; M65 ELISA

OXi4503 is a tubulin-binding vascular-disrupting agent (VDA), based on the structure of combretastatin (combretastatin-A1disodium-phosphate), which not only induces endothelial cell apoptosis but also has a direct cytotoxic effect on tumour cells (Hua et al, 2003). The drug has recently completed phase I evaluation as a potential anticancer drug at three different centres in the United Kingdom, the Mount Vernon Hospital in London, the Churchill Hospital in Oxford and the Christie Hospital in Manchester (Patterson et al, 2007). Preclinical studies demonstrated that in xenograft-bearing mice treated with a single dose of OXi4503 (100 $\left.\mathrm{mg} \mathrm{kg}^{-1}\right)$ apoptosis could occur in tumour endothelial cells as early as $1-3 \mathrm{~h}$ after drug administration, whereas secondary tumour cell necrosis was evident between 6 and $72 \mathrm{~h}$ (Sheng et al, 2004; Dalal and Burchill, 2009). In addition to acting as a VDA, OXi4503 can also undergo oxidative activation to a quinone intermediate to produce cytotoxicity by binding to protein thiols and nucleic acids, and stimulating oxidative stress through superoxide/hydrogen peroxide production (Folkes et al, 2007).

As part of the phase I evaluation of this compound several pharmacodynamic (PD) and biomarker assays have been

*Correspondence: Dr J Cummings; E-mail: jcummings@picr.man.ac.uk Revised 12 March 2012; accepted 26 March 2012; published online 26 April 2012 incorporated into the trial design, including two ELISAs that determine different circulating forms of the epithelial protein cytokeratin 18 (CK18) (Patterson et al, 2007). The M30 Apoptosense (M30) ELISA assay measures a caspase-cleaved product of CK18, termed CK18 ASP ${ }^{396}$, released from cells undergoing programmed cell death, and is believed to act as a quantitative and selective biomarker of apoptosis (Hagg et al, 2002; Biven et al, 2003). Thus, the M30 assay may detect the early wave of cell death associated with the direct action of the drug on endothelial cells, which have been demonstrated in previous studies to express CK18 (Stosiek et al, 1990; Miettinen and Fetsch, 2000; Merjava et al, 2009). In addition to measuring caspase-cleaved CK18, the M65 ELISA assay detects intact CK18 released from cells as they undergo necrosis, and is believed to act as a quantitative biomarker of total cell death (Kramer et al, 2004; Schutte et al, 2004). Thus, the M65 assay may detect the later wave of tumour cell necrosis that occurs as a consequence of drug-induced vascular collapse.

In order to capture and quantify both possible outcomes of OXi4503 treatment on cell death, blood samples for M30 and M65 ELISA analysis were collected from patients at an earlier $(4 / 6 \mathrm{~h})$ and a later time point $(24 \mathrm{~h})$ after the first administration of the drug. As the drug was administered three times weekly, blood collection time points were extended to day 8 and 15 after administration to establish whether the drug exhibited a sustained action on cell death. 


\section{MATERIALS AND METHODS}

\section{M30 and M65 ELISA methods}

M30 Apoptosense and M65 ELISA kits were both obtained from PEVIVA AB (Bromma, Sweden) and were operated essentially according to the manufacturer's instructions (http://www.peviva. com), as previously described in detail (Cummings et al, 2005; Cummings et al, 2006; Greystoke et al, 2008). Both kits are registered in accordance with the CE-IVD directive. Each assay reports concentrations in units, where $1 \mathrm{Ul}^{-1}$ is equivalent to 1.24 pм of a synthetic 21 amino-acid fragment of CK18 containing both M30 (e.g., M30) and M65 (e.g., M5) epitopes (Kramer et al, 2004). Calibration curves for the two assays consist of six non-zero concentrations of a recombinant peptide fragment of CK18 as the standard. Quality control samples comprising the same material as the calibration standard reconstituted in a buffer are included at high and low points on the calibration curves and were run in triplicate. Patient plasma samples were allowed to thaw at room temperature before analysis and were run in duplicate. Although M30 and M65 ELISAs do not exhibit good dilution linearity with patient-derived samples, this can be mitigated by dilution in blank plasma (Greystoke et al, 2008). When required, two dilutions were made per sample (e.g., 1 in 5 and 1 in 10), and antigen concentration was reported as the average of the back calculated values produced by the two dilutions.

\section{Patient sample collection protocol}

Blood samples for the separation of plasma for M30 and M65 ELISA analyses were collected from all eligible subjects entered into the Cancer Research UK-sponsored phase I Trial of OXi4503, where the drug was administered by $3 \times$ weekly intravenous infusions to patients with advanced solid tumours (CR-UK Protocol Number: PH1/098 and Eudra CT Number: 2004002375). The original sampling protocol for M30 and M65 ELISAs was limited to pre-dose, 1 and $24 \mathrm{~h}$ after dose. After the enrolment of two patients, the protocol was amended (Protocol Amendment 02: 15 September 2005) and samples were taken as follows: 0-7 days before, $4 \mathrm{~h}$ (Mount Vernon Hospital only), $6 \mathrm{~h}$ (Christie Hospital only) and $24 \mathrm{~h}$ after OXi4503 administration. From patient 16 onwards, the protocol was amended again to include an additional two samples for M30/M65 analysis at day 8 and 15 (five samples in total) from the first cycle and an allowance to collect samples from subsequent cycles of OXi4503 treatment. Eventually, the $4 / 6-\mathrm{h}$ time point was standardised to $4 \mathrm{~h}$ from patient 30 . A total of 45 subjects were entered into the trial.

\section{Patient sample processing before ELISA analysis}

At each time point specified above, a 4-ml aliquot of blood was collected into a heparin tube. Samples were inverted gently several times and kept on ice for no longer than $30 \mathrm{~min}$ until centrifugation at $1000 \mathrm{~g}$ at $4{ }^{\circ} \mathrm{C}$ for $10 \mathrm{~min}$. The upper plasma layer was transferred to a polypropylene tube and frozen upright at $-20^{\circ} \mathrm{C}$ before transfer to $-80^{\circ} \mathrm{C}$ for long-term storage. Samples were shipped by courier to the Paterson Institute for Cancer Research in Manchester in solid carbon dioxide, and confirmed to be frozen upon arrival.

\section{Efficacy of OXi4503 during the phase I trial}

Disease measurements and evaluation of efficacy followed the RECIST criteria to assess the best overall response (Therasse et al, 2000). Patients with measurable disease were placed into response categories of partial response (PR), stable disease (SD) and progressive disease (PD). The duration of $P R$ was evaluated from when the time measurement criteria were met until the first date that PD was objectively documented (taking as reference for PD the smallest measurements recorded since the treatment started). The duration of SD was measured from the start of the treatment until the criteria for PD were met, taking as reference the smallest measurements recorded since the treatment started. A minimum of two cycles (i.e., six infusions of OXi4503) were required for the evaluation of response. Clinical evidence of tumour progression during the first cycle of treatment was classified as early progression (EP).

\section{Statistical analysis}

All statistical analyses were conducted using GraphPad Prism Version 5.01 and 5.03 (GraphPad, San Diego, CA, USA), where $P$ values of $\leqslant 0.05$ were considered significant. As M30 and M65 plasma levels do not follow normal distributions in patients, only non-parametric analyses were conducted (Hou et al, 2009). To test for significance between different patient cohorts either the MannWhitney $U$ test or the Kruskal-Wallis test was employed.

\section{RESULTS}

Time and dose-dependent changes in M30 and M65 ELISA measurements after OXi4503 treatment

Percentage changes between baseline (pre-dose) levels of M30 and M65 antigens at course 1 and all subsequent time points within each patient were utilised to allow trends to emerge that might otherwise be obscured by large inter-patient variations in absolute concentrations. Initially, no discrimination was made between the different patient groups in order to focus on time and dosedependent drug effects.

Time-dependent percentage changes in both M30 and M65 levels after dose are presented in Figure 1. Although, there was no statistical significance between the different time points, interesting trends were evident. With the M30 ELISA there was a gradual increase in values to a peak $(14.2 \%)$ at 15 days after the first administration of OXi4503. In the case of M65, the greatest percentage increase (14.8\%) occurred after $24 \mathrm{~h}$ and then declined at subsequent time points. Significantly, there were no time-related decreases in M30 or M65 antigen levels that often signify a reduction in tumour burden (Hou et al, 2009).

When these temporal effects were equated against drug dose, the most striking effect on M30 antigen levels occurred at the $4 / 6$-h time point (Figure 2A). Interestingly, this was not mirrored

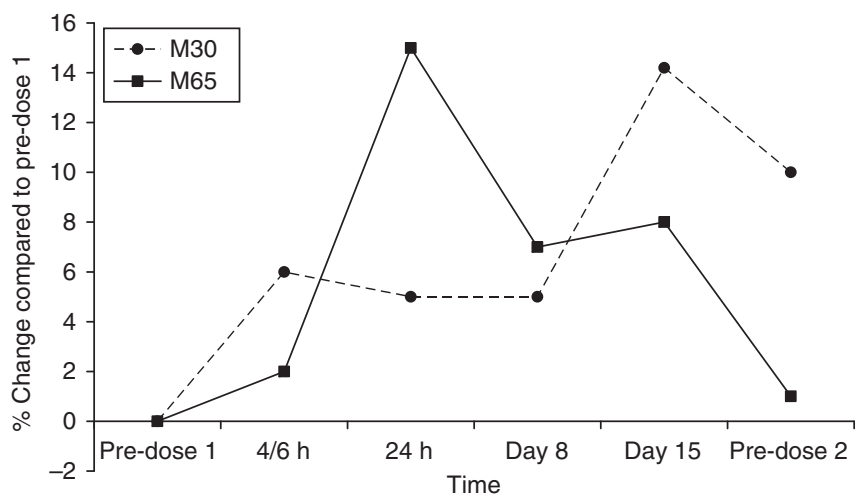

Figure I Mean percentage changes between baseline (pre-dose) levels and all subsequent time points measured by the M30 and M65 ELISAs. In this plot no discrimination was made between the different response groups identified during the phase I trial of OXi4503 or the dose received. Each point represents the mean value for all patients entered into the trial, and for clarity s.d. bars are not shown. 

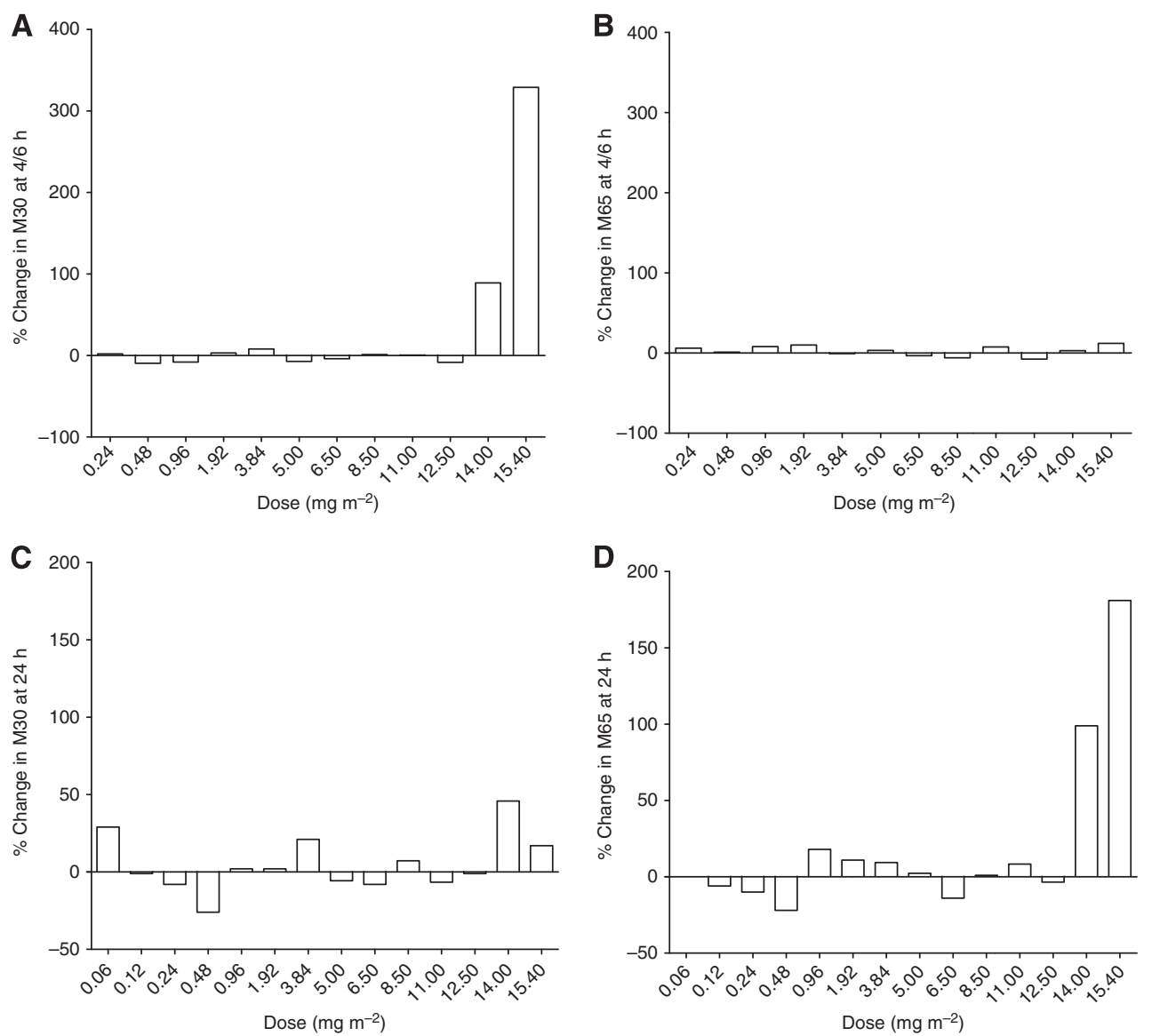

Figure 2 Mean percentage changes between baseline (pre-dose) levels and selected time points measured by the M30 and M65 ELISAs vs drug dose received. In this plot no discrimination was made between the different response groups identified during the phase I trial of OXi4503. (A) Mean percentage changes from baseline recorded at 4/6 h after drug administration by the M30 and (B), by M65 ELISAs. (C) Mean percentage changes from baseline recorded at $24 \mathrm{~h}$ after drug administration by the M30 and (D), by M65 ELISAs. Each bar represents the mean value for all the patients who received that particular dose.

by a concomitant elevation in M65 signal (Figure 2B). However, the apparent rise in M30 levels observed in Figure 1 at day 15 did not increase with dose rather it was evenly distributed across a range of doses (data not shown). The rise in M65 ELISA antigen levels detected at $24 \mathrm{~h}$ was also shown to be dosedependent, and to be of a similar magnitude to that of the M30 ELISA at $4 / 6 \mathrm{~h}(>100 \%$, Figure 2D). This increase was also not accompanied by a concomitant rise in M30 ELISA values at $24 \mathrm{~h}$ (Figure 2C).

Baseline (pre-dose) values generated by the M30 and M65 ELISAs in different patient-response groups

Previous studies have indicated that baseline values measured by the M30 and/or M65 ELISAs can predict for either response to treatment or disease progression (Ulukaya et al, 2007; Hou et al, 2009; Ozturk et al, 2009). To investigate whether any such relationships were evident in the OXi4503 trial, baseline values of M30 and M65 antigens are reported in Figure 3A (M30) and Figure 3B (M65), sub-divided into the three main groups of patients: EP, PD and SD/PR. There was no difference in M30 and M65 levels detected at baseline in the PD and SD groups. However, in the case of M65 ELISA, a significant trend towards higher levels in the EP group was recorded $(P=0.05$ compared with $\mathrm{PD}$ and $P=0.08$ compared with SD, Mann-Whitney $U$ test), indicating that in the OXi4503 cohort of patients, elevated pre-dose may relate to early disease progression.

\section{Time-dependent changes in M30 and M65 ELISA antigen concentrations in different patient-response groups}

Having identified time- and dose-dependent global changes in the M30 and M65 cell death ELISA measurements within the OXi4503 phase I population (as measured by a percent increase in value from baseline), the next stage was to assess whether these could be assigned to one of the three main patient groups of EP, PD and SD. At the 4/6-h time point, there were no significant differences in the percent change measured by both the M30 and M65 ELISAs in any of the three groups (Figure $4 \mathrm{~A}$ and $5 \mathrm{~A}$ ). However, at the 24-h time point a significant difference in M65 ELISA levels (but not M30) was detected in the SD group compared with the other two groups of EP and PD $(P=0.012$, the Mann-Whitney $U$ test; $P=0.015$ the Kruskal-Wallis test ) characterised by a mean increase in levels of $30.9 \%$ (Figure 4B and 5B). Apart from this result, there were no other significant differences between the three groups at any of the other time points studied.

\section{DISCUSSION}

In the present study, two serological assays that detect different circulating forms of the epithelial protein CK18 - the M30 and M65 ELISAs - have been applied as proof of principle pharmacodynamic biomarkers in the evaluation of OXi4503 during a phase I trial. Two main observations were made. First, M30 measured a selective dose-dependent increase in antigen levels at the earliest 

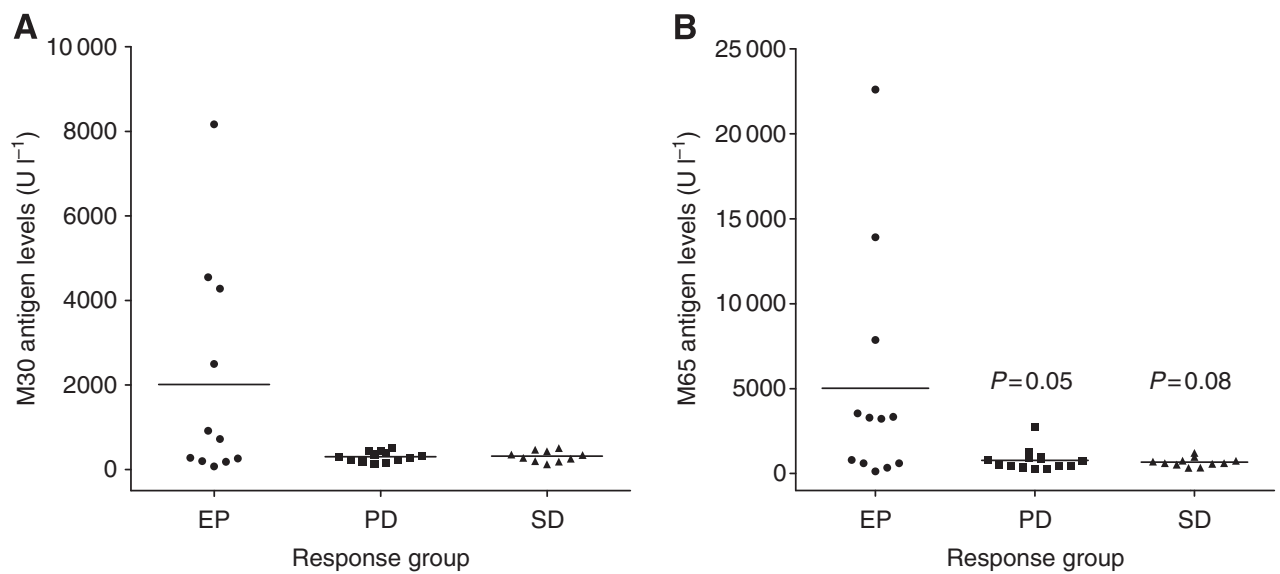

Figure 3 Baseline (pre-dose) antigen levels determined by M30 and M65 ELISAs after stratification into the three main patient groups identified during the phase I Trial of OXi4503: EP, PD and SD/PR. Graph (A) is for the M30 ELISA and graph (B) for the M65 ELISA. Each point represents an individual patient, and the bar represents the mean value for each group.
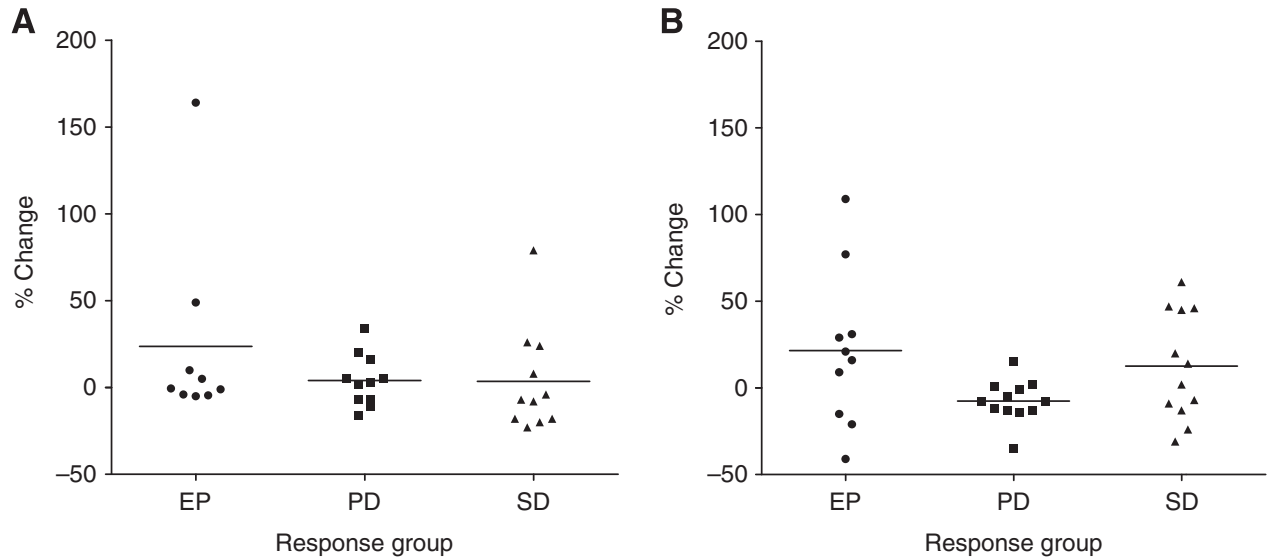

Figure 4 Percentage change in M30 antigen levels measured after drug treatment stratified into the three main patient groups identified during the phase I Trial of OXi4503: EP, PD and SD/PR. (A) Percentage change from baseline measured at $4 / 6 \mathrm{~h}$ after drug administration and (B) percentage change from baseline measured at $24 \mathrm{~h}$ after drug administration. Each point represents an individual patient, and the bar represents the mean value for each group.
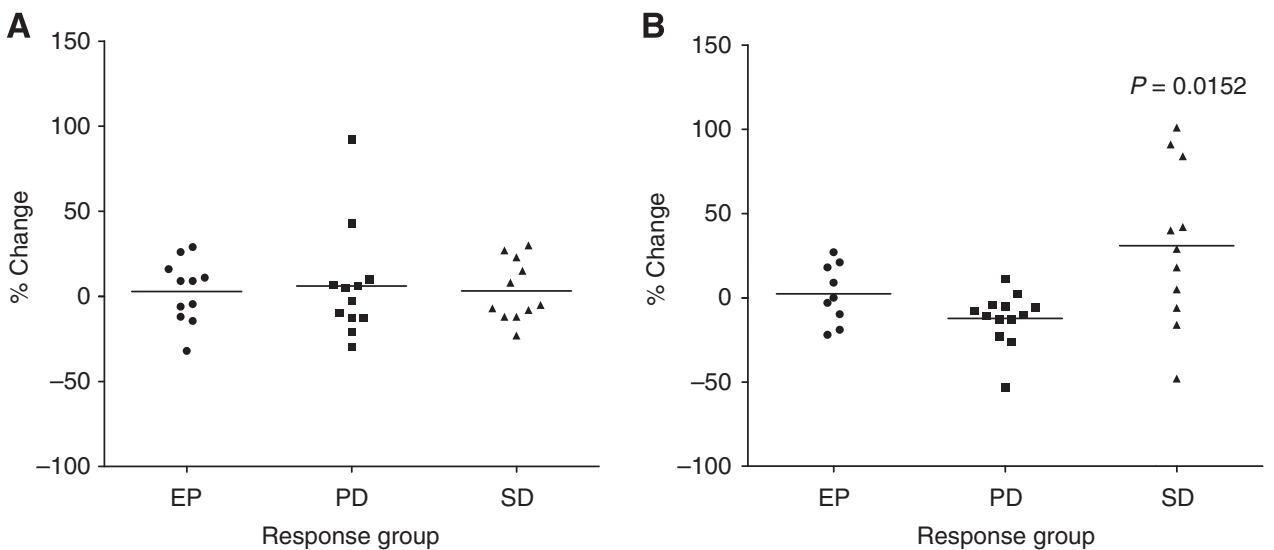

Figure 5 Percentage change in M65 antigen levels measured after drug treatment stratified into the three main different patient groups identified during the phase I Trial of OXi4503: EP, PD and (SD)/PR. (A) Percentage change from baseline measured at 4/6 h after drug administration and (B) percentage change from baseline measured at $24 \mathrm{~h}$ after drug administration. Each point represents an individual patient, and the bar represents the mean value for each group.

time point studied $(4 / 6 \mathrm{~h})$ whereas M65 measured a selective dose-dependent increase at $24 \mathrm{~h}$. Second, the increase in M65 concentrations detected $24 \mathrm{~h}$ after administration of OXi4503 was associated predominately (and significantly) with patients who exhibited SD/PR to the drug.
Assuming that M30 is a biomarker of apoptosis (Leers et al, 1999; Hagg et al, 2002; Biven et al, 2003) and that endothelial cells express CK18 (Stosiek et al, 1990; Miettinen and Fetsch, 2000; Merjava et al, 2009), and that M65 is a biomarker of non-apoptotic cell death (including necrosis) (Strnad et al, 2002; 
Kramer et al, 2004; Fisher et al, 2009), the dynamic changes detected in plasma would support the hypothesis that administration of OXi4503 to patients caused early apoptosis followed later by necrosis. Hence, these data appear to replicate closely the cell death profile of the drug observed in preclinical models (Sheng et al, 2004; Rice et al, 2011).

Reports of a selective drug-induced increase in the M30 signal in patients in the absence of a concomitant rise in M65 signal have appeared less frequently in the literature (Kramer et al, 2004; Hou et al, 2009). This is perhaps due to the fact that the M65 assay should theoretically detect caspase-cleaved CK18 (the M30 apoptotic signal) as well as the full length protein linked to necrosis (Kramer et al, 2004; Olofsson et al, 2007). Nevertheless, each of the two sandwich ELISAs utilise distinct antibodies for capture and detection, which can alter assay selectivity (De Petris et al, 2011). Moreover, the CK18-derived material present in the serum/plasma of cancer patients now appears to be more complex than that released from dying cells in culture, consisting of high molecular weight heteromeric keratin complexes (Olofsson et al, 2007). The diverse configurations adopted by these structures may preferentially restrict epitope accessibility and thus impact on the assay specificity (Findlay, 2008; Cummings et al, 2010).

A careful study of the release kinetics of CK18 fragments liberated from tumour cells undergoing programmed cell death in vitro has been conducted (Schutte et al, 2004). While caspase cleavage of CK18 was an early event $(2-4 \mathrm{~h})$, the subsequent cleaved forms and their complexes were retained in intact apoptotic bodies for a further $6-12 \mathrm{~h}$, before being released into medium upon loss of membrane integrity owing to secondary necrosis (Schutte et al, 2004). Such a prolonged time scale may militate against the appearance of significant levels of CK18cleaved complexes in the plasma of patients after only $4-6 \mathrm{~h}$. Nonetheless, a completely different situation may be present in vivo where apoptotic bodies are efficiently processed by phagocytosis (Linder et al, 2010). Here, saturation of clearance mechanisms has been postulated to allow stable keratin fragments to enter the circulation ( $\mathrm{Ku}$ et al, 1997; Leers et al, 2002; Schutte et al, 2004). Indeed, it has been estimated that to only double the plasma level of M30 antigen - caspase-cleaved CK18 $\mathrm{ASP}^{39}$ - as many as $10^{9}$ tumour cells would have to undergo apoptosis (Biven et al, 2003).

Other clinical investigations with agents known to induce early apoptosis - such as the inhibitor of antiapoptotic members of the Bcl-2 family ABT-263 (Navitoclax) - have demonstrated that elevations in caspase-cleaved CK18 can occur in the plasma of cancer patients within $6 \mathrm{~h}$ after drug administration (Gandhi et al, 2011). Imaging studies conducted in conjunction with the cell death biomarkers during the OXi4503 phase I confirmed early $(4 \mathrm{~h})$ dose-related pharmacodynamic activity in patients, manifest in this case as a reduction in DCE-MRI transfer constant consistent with vascular shutdown (Patterson et al, 2012). These latter clinical data also replicated closely the time scale for tumour vascular shutdown observed in preclinical xenograft models after treatment with OXi4503 (Hua et al, 2003; Sheng et al, 2004).

\section{REFERENCES}

Biven K, Erdal H, Hagg M, Ueno T, Zhou R, Lynch M, Rowley B, Wood J, Zhang C, Toi M, Shoshan MC, Linder S (2003) A novel assay for discovery and characterization of pro-apoptotic drugs and for monitoring apoptosis in patient sera. Apoptosis 8: $263-268$

Cummings J, Ranson M, Lacasse E, Ganganagari JR, St-Jean M, Jayson G, Durkin J, Dive C (2006) Method validation and preliminary qualification of pharmacodynamic biomarkers employed to evaluate the clinical efficacy of an antisense compound (AEG35156) targeted to the X-linked inhibitor of apoptosis protein XIAP. Br J Cancer 95: 42-48

Cummings J, Ward TH, Dive C (2010) Fit-for-purpose biomarker method validation in anticancer drug development. Drug Discov Today 15: 816-825
In a related phase I trial with the novel microtubule inhibitor and VDA CYT997, a dose-dependent increase in caspase-cleaved CK18 concentrations, at the same level of magnitude to that reported in the present study, was also detected by the M30 ELISA, $24 \mathrm{~h}$ after commencement of the drug infusion (Lickliter et al, 2010). Significantly, this rise in caspase-cleaved CK18 concentrations correlated closely to a similar rise in circulating levels of Von Willebrand factor (Lickliter et al, 2010), known to be present in high concentrations in endothelial cells and to increase in plasma following endothelial cell injury (Lee et al, 2005).

By comparison, a selective rise in M65 signal in the plasma of patients is theoretically possible, as only this assay can detect the intact CK18 component originating from cells undergoing necrotic cell death (Kramer et al, 2004). As with the M30, this selective increase corresponded to the preclinical profile of the drug where secondary haemorrhagic tumour cell necrosis was manifest after $24 \mathrm{~h}$ (Hua et al, 2003; Sheng et al, 2004). However, unlike M30 where this phenomenon was only evident after administration of the highest doses of OXi4503 (14 and $15.4 \mathrm{mg} \mathrm{m}^{-2}$ ), the M65 selective increase was also detected in patients receiving lower doses of drug (see below). Of note, in a trial subject who experienced tumour lysis syndrome, M65 recorded a large increase in circulating intact $\mathrm{CK} 18$ at $24 \mathrm{~h}$ corresponding to a 2.8 -fold rise in absolute concentration. Recruitment of intact CK18 from the microfilaments into a soluble exchangeable cytoplasmic pool occurs as an early stress response in cells, and is therefore potentially less time limited than the release of caspase-cleaved CK18 (Strnad et al, 2002).

The selective increase in M65 levels at $24 \mathrm{~h}$ appeared to associate significantly with patients in the SD/PR group. One may question whether a serological biomarker would be sufficiently sensitive to discriminate between limited response groups such as SD vs progression. However, support for this contention is provided by at least two independent publications (Olofsson et al, 2007; Scott et al, 2009). The first detected $>18 \%$ increase in M65 signal at $24 \mathrm{~h}$ in breast cancer patients treated with CEF chemotherapy who only exhibited a PR, in contrast to no increase in signal in nonresponding patients (Olofsson et al, 2007). In the second, baseline values of the M65 were significantly elevated in gastrointestinal cancer patients with PD compared with those with a partial/stable response to chemotherapy (Scott et al, 2009). Despite these reports, the present study represents one of the first, showing M65 ELISA measurements can potentially discriminate between different response groups during a phase I trial of a novel anticancer agent. In conclusion, pharmacodynamic evidence is presented as a proof of concept for OXi4503 mechanism of action in cancer patients. Inclusion of the M30 and particularly M65 ELISAs in further clinical evaluation of $\mathrm{OXi} 4503$ is recommended.

\section{ACKNOWLEDGEMENTS}

CR-UK and ECMC are acknowledged by JC, NS and CD for their financial support.
Cummings J, Ward TH, Lacasse E, Lefebvre C, St-Jean M, Durkin J, Ranson M, Dive C (2005) Validation of pharmacodynamic assays to evaluate the clinical efficacy of an antisense compound (AEG 35156) targeted to the X-linked inhibitor of apoptosis protein XIAP. Br J Cancer 92: $532-538$

Dalal S, Burchill SA (2009) Preclinical evaluation of vascular-disrupting agents in Ewing's sarcoma family of tumours. Eur J Cancer 45: 713-722

De Petris L, Branden E, Herrmann R, Sanchez BC, Koyi H, Linderholm B, Lewensohn R, Linder S, Lehtio J (2011) Diagnostic and prognostic role of plasma levels of two forms of cytokeratin 18 in patients with non-smallcell lung cancer. Eur J Cancer 47: 131-137 
Findlay JW (2008) Specificity and accuracy data for ligand-binding assays for macromolecules should be interpreted with caution. Aaps J 10: 433-434

Fisher MB, Zhang XQ, McConkey DJ, Benedict WF (2009) Measuring soluble forms of extracellular cytokeratin 18 identifies both apoptotic and necrotic mechanisms of cell death produced by adenoviral-mediated interferon alpha: possible use as a surrogate marker. Cancer Gene Ther 16: $567-572$

Folkes LK, Christlieb M, Madej E, Stratford MR, Wardman P (2007) Oxidative metabolism of combretastatin A-1 produces quinone intermediates with the potential to bind to nucleophiles and to enhance oxidative stress via free radicals. Chem Res Toxicol 20: 1885-1894

Gandhi L, Camidge DR, Ribeiro de Oliveira M, Bonomi P, Gandara D, Khaira D, Hann CL, McKeegan EM, Litvinovich E, Hemken PM, Dive C, Enschede SH, Nolan C, Chiu YL, Busman T, Xiong H, Krivoshik AP, Humerickhouse R, Shapiro GI, Rudin CM (2011) Phase I study of Navitoclax (ABT-263), a novel Bcl-2 family inhibitor, in patients with small-cell lung cancer and other solid tumors. J Clin Oncol 29: 909-916

Greystoke A, Cummings J, Ward T, Simpson K, Renehan A, Butt F, Moore D, Gietema J, Blackhall F, Ranson M, Hughes A, Dive C (2008) Optimisation of circulating biomarkers of cell death for routine clinical use. Ann Oncol 19: 990-995

Hagg M, Biven K, Ueno T, Rydlander L, Bjorklund P, Wiman KG, Shoshan M, Linder S (2002) A novel high-through-put assay for screening of pro-apoptotic drugs. Invest New Drugs 20: 253-259

Hou JM, Greystoke A, Lancashire L, Cummings J, Ward T, Board R, Amir E, Hughes S, Krebs M, Hughes A, Ranson M, Lorigan P, Dive C, Blackhall FH (2009) Evaluation of circulating tumor cells and serological cell death biomarkers in small cell lung cancer patients undergoing chemotherapy. Am J Pathol 175: 808-816

Hua J, Sheng Y, Pinney KG, Garner CM, Kane RR, Prezioso JA, Pettit GR, Chaplin DJ, Edvardsen K (2003) Oxi4503, a novel vascular targeting agent: effects on blood flow and antitumor activity in comparison to combretastatin A-4 phosphate. Anticancer Res 23: 1433-1440

Kramer G, Erdal H, Mertens HJ, Nap M, Mauermann J, Steiner G, Marberger M, Biven K, Shoshan MC, Linder S (2004) Differentiation between cell death modes using measurements of different soluble forms of extracellular cytokeratin 18. Cancer Res 64: 1751-1756

$\mathrm{Ku}$ NO, Liao J, Omary MB (1997) Apoptosis generates stable fragments of human type I keratins. J Biol Chem 272: 33197-33203

Lee KW, Lip GY, Tayebjee M, Foster W, Blann AD (2005) Circulating endothelial cells, von Willebrand factor, interleukin-6, and prognosis in patients with acute coronary syndromes. Blood 105: 526-532

Leers MP, Bjorklund V, Bjorklund B, Jornvall H, Nap M (2002) An immunohistochemical study of the clearance of apoptotic cellular fragments. Cell Mol Life Sci 59: 1358-1365

Leers MP, Kolgen W, Bjorklund V, Bergman T, Tribbick G, Persson B, Bjorklund P, Ramaekers FC, Bjorklund B, Nap M, Jornvall H, Schutte B (1999) Immunocytochemical detection and mapping of a cytokeratin 18 neo-epitope exposed during early apoptosis. I Pathol 187: $567-572$

Lickliter JD, Francesconi AB, Smith G, Burge M, Coulthard A, Rose S, Griffin M, Milne R, McCarron J, Yeadon T, Wilks A, Cubitt A, Wyld DK, Vasey PA (2010) Phase I trial of CYT997, a novel cytotoxic and vasculardisrupting agent. Br J Cancer 103: 597-606
Linder S, Olofsson MH, Herrmann R, Ulukaya E (2010) Utilization of cytokeratin-based biomarkers for pharmacodynamic studies. Expert Rev Mol Diagn 10: 353-359

Merjava S, Neuwirth A, Mandys V, Jirsova K (2009) Cytokeratins 8 and 18 in adult human corneal endothelium. Exp Eye Res 89: 426-431

Miettinen M, Fetsch JF (2000) Distribution of keratins in normal endothelial cells and a spectrum of vascular tumors: implications in tumor diagnosis. Hum Pathol 31: 1062-1067

Olofsson MH, Ueno T, Pan Y, Xu R, Cai F, van der Kuip H, Muerdter TE, Sonnenberg M, Aulitzky WE, Schwarz S, Andersson E, Shoshan MC, Havelka AM, Toi M, Linder S (2007) Cytokeratin-18 is a useful serum biomarker for early determination of response of breast carcinomas to chemotherapy. Clin Cancer Res 13: 3198-3206

Ozturk B, Coskun U, Sancak B, Yaman E, Buyukberber S, Benekli M (2009) Elevated serum levels of M30 and M65 in patients with locally advanced head and neck tumors. Int Immunopharmacol 9: 645-648

Patterson DM, Ross P, Koetz B, Saleem A, Stratford M, Stirling J, Padhani A, Asselin M, Price P, Rustin GJ (2007) Phase I evaluation of OXi4503, a vascular disrupting agent, in patients with advanced solid tumours. J Clin Oncol 25: 14146

Patterson DM, Zweifel M, Middleton MR, Price PM, Folkes LK, Stratford MR, Ross P, Halford S, Peters J, Balkissoon J, Chaplin DJ, Padhani AR, Rustin GJ (2012) Phase I clinical and pharmacokinetic evaluation of the vascular-disrupting agent OXi4503 in patients with advanced solid tumors. Clin Cancer Res 18: 1415-1425

Rice L, Pampo C, Lepler S, Rojiani AM, Siemann DW (2011) Support of a free radical mechanism for enhanced antitumor efficacy of the microtubule disruptor OXi4503. Microvasc Res 81: 44-51

Schutte B, Henfling M, Kolgen W, Bouman M, Meex S, Leers MP, Nap M, Bjorklund V, Bjorklund P, Bjorklund B, Lane EB, Omary MB, Jornvall H, Ramaekers FC (2004) Keratin 8/18 breakdown and reorganization during apoptosis. Exp Cell Res 297: 11-26

Scott LC, Evans TR, Cassidy J, Harden S, Paul J, Ullah R, O’Brien V, Brown $\mathrm{R}$ (2009) Cytokeratin 18 in plasma of patients with gastrointestinal adenocarcinoma as a biomarker of tumour response. Br J Cancer 101: $410-417$

Sheng Y, Hua J, Pinney KG, Garner CM, Kane RR, Prezioso JA, Chaplin DJ, Edvardsen K (2004) Combretastatin family member OXI4503 induces tumor vascular collapse through the induction of endothelial apoptosis. Int J Cancer 111: 604-610

Stosiek P, Kasper M, Conrad K (1990) [Immunohistochemistry of cytokeratin expression in human blood vessel endothelia with special reference to synovial connective tissue]. Acta Histochem 89: 61-66

Strnad P, Windoffer R, Leube RE (2002) Induction of rapid and reversible cytokeratin filament network remodeling by inhibition of tyrosine phosphatases. J Cell Sci 115: 4133-4148

Therasse P, Arbuck SG, Eisenhauer EA, Wanders J, Kaplan RS, Rubinstein L, Verweij J, Van Glabbeke M, van Oosterom AT, Christian MC, Gwyther SG (2000) New guidelines to evaluate the response to treatment in solid tumors. European Organization for Research and Treatment of Cancer, National Cancer Institute of the United States, National Cancer Institute of Canada. J Natl Cancer Inst 92: 205-216

Ulukaya E, Yilmaztepe A, Akgoz S, Linder S, Karadag M (2007) The levels of caspase-cleaved cytokeratin 18 are elevated in serum from patients with lung cancer and helpful to predict the survival. Lung Cancer 56: 399-404

This work is published under the standard license to publish agreement. After 12 months the work will become freely available and the license terms will switch to a Creative Commons Attribution-NonCommercial-Share Alike 3.0 Unported License. 